\section{Prof. Michelson's Work in Astronomical Interferometry.}

$\mathrm{M}^{\mathrm{R}}$ R. POST - WHEELER, who is on the staff of the American Embassy, attended at the annual general meeting of the Royal Astronomical Society on February 9 to receive the gold medal on behalf of Prof. A. A. Michelson, who was unable to be present himself.

Prof: Eddington gave a most illuminating address on the reasons of the award, explaining that the necessity for the great separation of the mirrors receiving the pencils of light from the stars was to give sufficient difference of length of path to enable the rays from the two extremities of a diameter of the star to be in opposite phase, so that the bright regions of the image from one extremity should fall on the dark regions of the other and so cause the fringes to vanish. It was mentioned that the method had been successfully applied to the measurement of the diameters of Jupiter's satellites, but the stars seem to have been considered hopeless, till recent physical work on the distribution of energy in the spectrum led to the conclusion that the red stars have such dull surfaces that the brighter ones must have appreciable discs in order to give so much light.

The actual figure had been calculated for Betelgeuse, and the observed diameter afterwards proved to be very close to it.

Some letters from Mr. Pease were read, in which he described the great practical difficulties that were incurred in applying the method of diffraction fringes, and the long-continued trials that were finally crowned with success. One of the earliest successes was the determination of the orbit of Capella. This gave, for the first time, a really accurate value of the mass and absolute magnitude of a giant star, which had already proved of use in the physical studies that were being made on these bodies.

A recent interesting development of the Betelgeuse measures was that the diameter came out different at different times, to an extent much beyond the probable errors of the measures. Attempts were being made to correlate these changes with the variable brightness and variable radial velocity of the star, but it will be necessary to carry on these measurements for some time before a definite conclusion could be reached.

Prof. Edclington went on to point out that the famous Michelson-Morley experiment, for which the Copley medal of the Royal Society was awarded in 1907 , though not specially contemplated in the present award, might be considered as coming within its terms ; for the measures were made by interference methods, and the question whether the movement of the earth through the ether could be detected was one of the highest astronomical interest. He knew that their medallist was disappointed at the negative result, but the whole of the system of relativity had been founded upon it, so that in his (Prof. Eddington's) opinion it was more fruitful than a positive result would have been.

In handing the medal to Mr. Post-Wheeler he asked him to transmit to Prof. Michelson their congratulations on his success and their good wishes for the long continuance of his fruitful labours. Mr. Post-Wheeler replied in a few suitable words expressing his sense of the pleasure it gave him to be there as the representative of America, and thanking the Society for the honour they had conferred upon bis country.in the person of Prof. Michelson.

\section{University and Educational Intelligence.}

Birmingham.-The Mitsui family of Japan has made a gift of $5000 l$. to the faculty of commerce. The Council has decided to apply the gift to the foundation of a chair of finance which, in view of the personal connexion of the Mitsui family with the university and of their generous contribution to its funds, is to be designated the Mitsui professorship of finance.

Mr. F. W. M. Lamb has been appointed assistant lecturer in pathology.

At the annual meeting of the Court of Governors, the principal appealed for more assistance from the districts surrounding the city. These districts at present contribute only $3500 l$. per annum to the university as against $15,000 l$. given by the city, although half the students come from outside the city.

CAmbridge.-Mr. J. B. S. Haldane, New College, Oxford, and Trinity College, has been appointed Sir William Dunn's reader in biochemistry. Mr. A. Hutchinson, Pembroke College, has been appointed University lecturer in crystallography. Dr. C. Shearer, Clare College, has been appointed University lecturer in embryology.

Manchester.-The following lecturers have been appointed : physics, Dr. J. C. M. Brentano; engineering, Mr. H. W. Baker ; biological chemistry, Mr. A. D. Ritchie.

OXFORD.-The vice-chancellor has appointed Sir Archibald E. Garrod, Regius professor of medicine and student of Christ Church, to act as deputy for the current term to Dr. Rudolph A. Peters, fellow of Gonville and Caius College, Cambridge, who has recently been elected Whitley professor of biochemistry in succession to the late Prof. Benjamin Moore.

The Weldon memorial prize, which was founded in 1907 by friends of the late Prof. Weldon, to perpetuate his memory and to encourage biometric science, has been awarded to Dr. Johannes Schmidt, director of the Carlsberg Laboratory, Copenhagen. This prize is awarded every three years, without regard to nationality, sex, or membership of any university, to the person who, in the judgment of the electors, has, in the six years next preceding the date of the award, published the most noteworthy contribution to biometric science. Previous recipients of the prize have belonged to St. Andrews, London, and Washington University, St. Louis. On one occasion it was awarded to a lady, Miss Ethel M. Elderton, fellow of University College, London.

SheFField.-Mr. W. Vickers has been appointed lecturer in education and master of method.

Prof. R. V. Wheeler, professor of fuel technology in the University of Sheffield, has been awarded the Greenwell medal of the North of England Institution of Mining and Mechanical Engineers, for his researches on coal.

THE first of a special series of lectures on " Master Minds and their Work," arranged in connexion with the London County Council's scheme of lectures for teachers, was delivered at King's College on February I 4 by Dr. Charles Singer, whose subject was Leonardo da Vinci (I452-I5I9). The object 
of the series is to illustrate, by the history of the work and influence of a few great men of various nationalities, the truth that in the study of the history of science is to be found a strong appeal to the spirit of community among men. It is suggested that this line of study will show that all nations have borne their share in building up the structure of knowledge according to the opportunities and civilisation of the times. Succeeding lectures are as follows:-February 2I, Descartes (I596-I650), Prof. H. Wildon Carr ; February 28, Newton (I642I727), Prof. A. R. Forsyth ; March 7, Pasteur (I 822I895), Sir D'Arcy Power; March I4, Helmholtz (I82I-I893), Sir W. M. Bayliss; March 2I (at University College, Gower Street, W.C.r.), Darwin (1809-1882), Prof. Karl Pearson.

THE annual prize distribution was held at the Sir John Cass Technical Institute on Wednesday, January $3 \mathrm{I}$, and the awards were distributed by Sir Thomas Holland. The chairman of the governing body, the Rev. J. F. Marr, in giving a summary of the work of the Institute during the past session, stated that during this period a total of I073 students had been in attendance-the highest figure yet attained. The year had not been an easy one, for financial considerations were and still are conspicuously in the foreground. The needs of technical education cannot be satisfactorily met without mutual trust and confidence between the public authorities and those administering the funds placed at their disposal, and without a full belief in the national value of technical education. Despite the restricted accommodation in the science departments, 3I students had been engaged in research work and five papers had been published, bringing the total number of original investigations issued from the Institute to I2O. For the second year in succession a student of the metallurgy department had been awarded the first prize (Silver Medal) in the City and Guilds of London Institute examination in non-ferrous metallurgy.

The Attorney-General, Sir Douglas McGarel Hogg, distributed the prizes at the Borough Polytechnic on Friday, February 2. Mr. J. Leonard Spicer, chairman of the governors, referred to the fact that Sir Douglas Hogg's father, Mr. Quintin Hogg, was the founder of the great Polytechnic in Regent Street, and Sir Douglas himself had throughout his life been associated with that Institute. Sir Douglas Hogg, in his address, said with regard to the work of the Institute, that it was not their desire to turn out a number of half-fledged amateurs to compete with the men in the workshops, but by technical instruction to enable those in the workshops to make themselves more efficient and to make greater progress in the industry to which they belonged. The policy of the governors in supplementing the experience of the workshop by trade instruction, and of selecting teachers who themselves had worked in the trades, is undoubtedly sound. The women's side of the Polytechnic is strong, and some of the activities of the Borough Polytechnic are unique in the south-eastern counties of England; the School of Bakery and Confectionery has no parallel, and the Department of Painters' Oils, Colours and Varnishes represents highly specialised and valuable technological departments. The Polytechnic has received valuable assistance from expert trade committees, trades unions, and associations of employers, in order to keep its work closely related to the current needs of industry. Principal Bispham, in his report, stated that both in quality and bulk the work of the past session was a record one and altogether a worthy tribute to the former principal, Mr. C. T. Millis, who has recently retired.

\section{Societies and Academies.}

\section{LONDON.}

Royal Society, February 8.-L. Bairstow, Miss B. M. Cave, and Miss E. D. Lang: The resistance of a cylinder moving in a viscous fluid. The equations of motion of a viscous fluid in the approximate form proposed by Oseen are taken as a basis for calculations of the resistance of a circular cylinder and the surface friction along a plane. In the case of the circular cylinder experimental information obtained at the N.P.L. is wholly suitable for the purposes of comparison with the present calculations. A resistance coefficient is found which is about 30 per cent. greater than that observed at the limit of the range of observation. Calculations for the plane show singularities at the edges, but lead to a resistance which is in rough agreement with experiment.G. I. Taylor: The motion of ellipsoidal particles in a viscous fluid. According to Dr. G. B. Jeffery ellipsoidal particles immersed in a moving viscous fluid assume certain definite orientations in relation to the motion of the fluid. Ellipsoidal particles of aluminium and immersed in water glass take up such positions, but they take a long time to get to those positions. In the meanwhile they oscillate in the way indicated in Dr. Jeffery's analysis.-W. E. Dalby: Further researches on the strength of materials. In a new apparatus, an alternating load, push and pull, can be applied to a test piece in such a way that the curves of load and elastic extension are recorded photographically. The yield in tension and compression is found to be substantially the same, and the modulus of elasticity is the same, but alternating load is met by alternating response. When a load of either sign is removed the response is elastic, but imperfectly so. When a load is re-applied, but of opposite sign to the load removed, the response is mainly plastic. By means of a new instrument an alternating torque can be applied to a test piece in such a way that the curves of torque and elastic twist are recorded photographically. This shows that alternating torque is met by an alternating response in shear. It is possible to predict a practical fatigue limit from these diagrams.-Lewis F. Richardson: Theory of the measurement of wind by shooting spheres upward. A steel sphere, about the size of a pea or a cherry, is shot upwards from a gun, which is not rifled. The gun is inclined from the vertical towards the advancing air, and the tilt adjusted by trial until the returning sphere falls very close to the gun. The tilt is then some measure of a weighted average of the wind, in the region extending from the ground up to the maximum height attained. This height is found from the time of absence of the sphere. The observation of the tilt and time is repeated for greater and greater heights in succession. Mathematically speaking, the problem involves a " linear integral equation of the first kind," which is solved approximately by transforming it into a moderate number of algebraic simultaneous equations. In the general part of the theory an approximation which fails at the vertex of the trajectory is made. A special and sufficiently correct theory or a correction to the general theory meets this difficulty.Ernest Wilson: On the susceptibility of feebly magnetic bodies as affected by tension. When magnetite is subjected to tensile stress of 50-130 kgrm. per sq. $\mathrm{cm}$. as a maximum, the susceptibility for a given-value of the magnetic force at first increases and then decreases as the specific load continuously increases, and exhibits a reversal point as in iron. The magnetic force at which the percentage increase in permeability has a maximum value is 